\title{
Efficacy of Two Types of Toothbrushes in Patients Undergoing Orthodontic Treatment with Fixed Appliance
}

\author{
Nikhil Kumar ${ }^{1 *}$ Bidisha Sikdar $^{2}$ Arya Priyadarshinii ${ }^{3}$ Amrita Pritam ${ }^{4}$ Jyoti Kumari $^{5}$ Ujjwal Kunal $^{6}$
}

\begin{abstract}
${ }^{1}$ PG Student, Department of Pedodontics and Preventive Dentistry, Vananchal Dental College and Hospital, Garhwa, Jharkhand, India. 2PG Student, Department of Orthodontics \& Dentofacial Orthopedics, Vananchal Dental College and Hospital, Garhwa, Jharkhand, India. 3PG Student, Department of Orthodontics \& Dentofacial Orthopedics, Vananchal Dental College and Hospital, Garhwa, Jharkhand, India. 4PG Student, Department of Orthodontics \& Dentofacial Orthopedics, Vananchal Dental College and Hospital, Garhwa, Jharkhand, India. ${ }^{5}$ PG Student, Department of Orthodontics \& Dentofacial Orthopedics, Vananchal Dental College and Hospital, Garhwa, Jharkhand, India.
\end{abstract}

6Private Consultant, Patna, Bihar, India.

\section{ABSTRACT}

Aim: The aim of the study was to evaluate the efficacy of an orthodontic toothbrush in comparison to a normal toothbrush.

Materials and methods: The patients were randomly divided into two groups. Group A received Colgate orthodontic brushes for oral hygiene maintenance whereas, and group B received normal toothbrush. Data of the patients regarding their age, sex, type of toothbrush, gingival index (GI), and plaque index (PI) were collected.

Results: The average plaque index of group A using an orthodontic brush before orthodontic brackets were 1.37, and two months after bonding was 1.48. The average plaque index what patients using a conventional brush before putting brackets was 1.41 , and 1.67 at the end of two months. The gingival index in group A at the baseline was 1.44 and 1.48 at the end of two months. Similarly, the gingival index of group B at baseline was 1.46 and 1.72 at the end of two months.

Conclusion: There is no significant difference in the clinical efficacy of both the type of brushes in the patients who are undergoing orthodontic treatment.

Keywords: Conventional toothbrush, orthodontic toothbrush, plaque control.

\section{INTRODUCTION}

Patients undertaking orthodontic treatment with fixed appliances face a difficult oral hygiene situation. Orthodontic bands, brackets, and wires are impediments to brushing and flossing, thus facilitating the accumulation of plaque and compromising gingival health. It is well documented that orthodontic treatment with fixed appliances is accompanied by an increased risk of caries ${ }^{1-4}$ and gingivitis ${ }^{5,6}$. Microbiological changes after the insertion of orthodontic appliances have been demonstrated. Increasing numbers of Streptococcus mutans and lactobacilli after bonding of fixed appliances have been described ${ }^{7}$. Other reports revealed statistically significant increases in suspected periodontal pathogens such as spirochetes, motile rods, and other gram-negative organisms $^{8}$.

It is a known fact that the accumulation of dental plaque is a very important etiologic factor of caries and periodontal diseases. ${ }^{9}$ The plaque initiates the inflammatory process, which releases the prostaglandins and intern it leads to bone loss. ${ }^{10-12}$ This bone loss ultimately leads to tooth loss. Applications of fluoride are advised to reduce these unwanted effects. ${ }^{13}$

Received: Jan. 3, 2021: Accepted: Mar. 2, 2021

*Correspondence Dr. Nikhil Kumar.

Department of Pedodontics and Preventive Dentistry, Vananchal Dental College and Hospital, Garhwa, Jharkhand, India.

Email: Not Disclosed

Doi: https://doi.org/10.53064/jrad.2021.12.1.04

Copyright (C)2021

\begin{tabular}{l|l} 
WWW.jrad.co.in & pISSN 2278-0076 \\
eISSN 2321-9270
\end{tabular} 


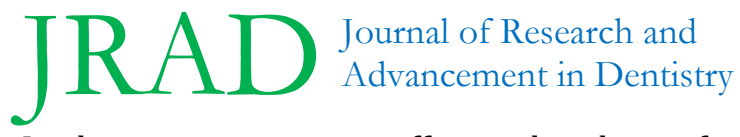

In these circumstances, effective brushing of teeth becomes very important. They still remain the most important preventive measures. Various types of toothbrushes are available in the market. Health professionals, along with doctors, gets confused regarding the best available toothbrush. The aim of the study was to evaluate the efficacy of an orthodontic toothbrush in comparison to a normal toothbrush.

\section{MATERIALS AND METHODS}

The subjects were selected from the outpatient's department of orthodontics. Those subjects who were following the oral hygiene methods were selected for the study. Forty patients were included in the study. Out of the forty, 31 were males, and the remaining 9 were females. Prior to the start of the study, all the patients have explained the details of the study and written consent were taken. Ethical clearance was obtained from the institutional review board (RDC/2019/32/002).

The subjects who had not received any periodontal therapy for the past six months, who had not taken antibiotics for the past fifteen days, and who were willing to visit for recall were included in this study. The patients were randomly divided into two groups (Group A and Group B) by the coin toss method. Group A received Colgate orthodontic brushes (Colgate-Palmolive, India, Ltd) for oral hygiene maintenance whereas, group B received normal toothbrush.

In this study, the subjects and doctors were blinded regarding the product and group. Data of the patients regarding their age, sex, type of toothbrush, gingival index (GI), and plaque index (PI) were collected. All the clinical data recording was done by the same health professional in order to reduce intra examiner bias.

All the recommended oral hygiene instructions were given to all the subjects at the baseline and all the recall visits. Scaling was done for all the subjects. PI and GI were made at baseline just before fixing the brackets. Patients were recalled at one month and two months' time.
Kumar $\mathrm{N}$ et al.

\section{RESULTS}

Table 1: Results for Plaque Index.

\begin{tabular}{|l|l|l|l|l|}
\hline Type & BM & $1 \mathrm{M}$ & $2 \mathrm{M}$ & P value \\
\hline $\begin{array}{l}\text { Orthodontic } \\
\text { Brush }\end{array}$ & 1.37 & 1.51 & 1.48 & 0.418 \\
\hline $\begin{array}{l}\text { Normal } \\
\text { Brush }\end{array}$ & 1.43 & 1.59 & 1.67 & 0.418 \\
\hline P value & 0.543 & 0.434 & 0.138 & \\
\hline
\end{tabular}

Table 2: Results for Gingival Index.

\begin{tabular}{|l|l|l|l|l|}
\hline Type & BM & $1 \mathrm{M}$ & $2 \mathrm{M}$ & P value \\
\hline $\begin{array}{l}\text { Orthodontic } \\
\text { Brush }\end{array}$ & 1.44 & 1.51 & 1.48 & 0.845 \\
\hline $\begin{array}{l}\text { Normal } \\
\text { Brush }\end{array}$ & 1.46 & 1.61 & 1.72 & 0.845 \\
\hline P value & 0.860 & 0.416 & 0.035 & \\
\hline
\end{tabular}

The plaque index and gingival index was found to be significant at two months' time. This indicated a significant reduction in plaque and hence gingivitis. The average plaque index of group A using orthodontic brush before orthodontic brackets were 1.37 , one month after bonding was 1.51 . and two months after bonding was 1.48. The average plaque index what patients using a conventional brush before putting brackets was 1.41 , and 1.67 at the end of two months.

The gingival index in group $\mathrm{A}$ at the baseline was 1.44 at the end of one month, 1.51, and 1.48 at the end of two months. Similarly, the gingival index of group B at baseline was 1.46, at the end of 1 month was 1.62 , and 1.72 at the end of two months.

\section{DISCUSSION}

Maintaining good oral hygiene is a need for patients undergoing orthodontic treatment. Plaque around the appliance causes gingivitis and decalcification of the gingiva. ${ }^{14}$ An orthodontist needs to advise the patients about different plaque control methods and also needs to note the effectiveness of the oral hygiene that was prescribed.15 An orthodontic appliance tends to increase the plaque retentive areas hence the need for effective plaque control methods becomes of utmost importance. ${ }^{16}$ An advice regarding effective plaque control methods has three objectives: prevention of decalcification, reduction of gingival inflammation, and preserving orthodontic appliance. ${ }^{17}$ Fixed orthodontic 
JRAD

Journal of Research and

Advancement in Dentistry

appliances can prevent both effective toothbrushing and mechanical cleaning action of mastication, leading to plaque accumulation. ${ }^{18}$ Orthodontic treatment takes a long time and considering this fact, and oral hygiene methods should be taken very seriously. It should include professional cleaning along with home care methods. Mechanical removal of black is the best possible way to keep the oral.

In the current study, the efficacy of two plaque removal toothbrushes was compared. A doubleblind study was done to prevent bias. The patient selected were of the age group of 15 to 25 years. They were instructed to follow a good oral hygiene method. Patients were instructed to brush daily, first in the morning and then at night. The duration of brushing will fix to three minutes. Patients were prevented from the use of mouthwash and topical fluorides to keep the uniformity among all the subjects. Mouthwashes may be helpful to reduce dental plaque formation, although the application of topical provides one of the most effective caries prevention methods.

Several studies have shown the different black control methods yield similar results. ${ }^{19}$ In order to facilitate plaque control in an orthodontic patient, specially designed manual toothbrushes have been developed. Brushes with v-shaped grooves were manufactured to gain maximum plaque removal all around the brackets and archwires. However, their effectiveness in reducing gingivitis when compared to conventional brushing was questionable. Such staged brushes showed significantly superior cleaning efficacy independent of the bracket area size in the in-vitro experiment. The findings confirm the results of a previous in vitro study, which showed that different bristle arrangements, such as lowered bristles in the middle of the brush field, have improved cleaning efficacy than planar bristle fields. Toothbrushes with a flat profile proved to be unsatisfactory for the cleaning of teeth with brackets. It has, however, also been shown that certain toothbrushes have different cleaning effects when used with varying degrees of the force application. At high load, soft or fine bristles may become twisted, resulting in lower cleaning efficacy. With low force, interaction with the tooth surfaces increases since soft bristles allow penetration into the interproximal and inter bracket area.
Kumar $\mathrm{N}$ et al.

\section{CONCLUSION}

This study shows that there is no difference in efficacy among conventional brushes and orthodontic brushes on the patients undergoing orthodontic treatment.

\section{CONFLICTS OF INTEREST}

The authors declare they have no potential conflict of interests regarding this article.

\section{REFERENCES}

1. Zachrisson BU. Cause and prevention of injuries to teeth and supporting structures during orthodontic treatment. Am J Orthod. 1976 Mar;69(3):285-300.

2. O'Reilly MM, Featherstone JD. Demineralization and remineralization around orthodontic appliances: an in vivo study. Am J Orthod Dentofac Orthop Off Publ Am Assoc Orthod Its Const Soc Am Board Orthod. 1987 Jul;92(1):33-40.

3. Abou Neel EA, Aljabo A, Strange A, Ibrahim S, Coathup M, Young AM, et al. Demineralizationremineralization dynamics in teeth and bone. Int J Nanomedicine. 2016 Sep 19;11:4743-63.

4. Jahanimoghadam F. Dental Anomalies: An Update. Adv Hum Biol. 2016;6(3):112.

5. Boyd RL, Leggott PJ, Quinn RS, Eakle WS, Chambers D. Periodontal implications of orthodontic treatment in adults with reduced or normal periodontal tissues versus those of adolescents. Am J Orthod Dentofac Orthop Off Publ Am Assoc Orthod Its Const Soc Am Board Orthod. 1989 Sep;96(3):191-8.

6. Huser MC, Baehni PC, Lang R. Effects of orthodontic bands on microbiologic and clinical parameters. Am J Orthod Dentofac Orthop Off Publ Am Assoc Orthod Its Const Soc Am Board Orthod. 1990 Mar;97(3):213-8.

7. Liu J, Bian Z, Fan M, He H, Nie M, Fan B, et al. Typing of mutans streptococci by arbitrarily primed PCR in patients undergoing orthodontic treatment. Caries Res. 2004 Dec;38(6):523-9.

8. Perinetti G, Paolantonio M, Serra E, D'Archivio D, D'Ercole S, Festa F, et al. Longitudinal monitoring of 


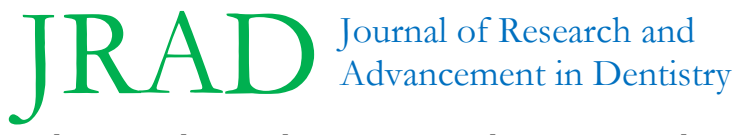

subgingival colonization by Actinobacillus actinomycetemcomitans, and crevicular alkaline phosphatase and aspartate aminotransferase activities around orthodontically treated teeth. J Clin Periodontol. 2004 Jan;31(1):60-7.

9. Loesche WJ. Microbiology of Dental Decay and Periodontal Disease. In: Baron S, editor. Medical Microbiology [Internet]. 4th ed. Galveston (TX): University of Texas Medical Branch at Galveston; 1996 [cited 2020 Jul 23]. Available from: http://www.ncbi.nlm.nih.gov/books/NBK8259/

10. Graves DT, Li J, Cochran DL. Inflammation and Uncoupling as Mechanisms of Periodontal Bone Loss. J Dent Res. 2011 Feb;90(2):143-53.

11. Hansson GK, Libby P, Tabas I. Inflammation and plaque vulnerability. J Intern Med. 2015 Nov;278(5):483-93.

12. Kalyan P, Dave B, Deshpande N, Panchal D. A study to assess the periodontal status of eunuchs residing in Central Gujarat, India: A cross-sectional study. Adv Hum Biol. 2020;10(3):162.

13. Everett ET. Fluoride's Effects on the Formation of Teeth and Bones, and the Influence of Genetics. J Dent Res. 2011 May;90(5):552-60.

14. Pandey V, Chandra S, Dilip Kumar HP, Gupta A, Bhandari PP, Rathod P. Impact of dental neglect score on oral health among patients receiving fixed orthodontic treatment: A cross-sectional study. J Int Soc Prev Community Dent. 2016;6(2):120-4.

\section{Kumar $\mathrm{N}$ et al.}

15. Shilpa M, Jain J, Shahid F, Gufran K, Sam G, Khan MS. Efficacy of Three Types of Plaque Control Methods During Fixed Orthodontic Treatment: A Randomized Controlled Trial. J Pharm Bioallied Sci. 2019 May;11(Suppl 2):S246-51.

16. Ousehal L, Lazrak L, Es-Said R, Hamdoune H, Elquars F, Khadija A. Evaluation of dental plaque control in patients wearing fixed orthodontic appliances: a clinical study. Int Orthod. 2011 Mar;9(1):140-55.

17. Axelsson P, Lindhe J, Wäseby J. The effect of various plaque control measures on gingivitis and caries in schoolchildren. Community Dent Oral Epidemiol. 1976 Nov;4(6):232-9.

18. Metin-Gürsoy G, Uzuner FD. The Relationship between Orthodontic Treatment and Dental Caries. In: Akarslan Z, editor. Dental Caries - Diagnosis, Prevention and Management [Internet]. InTech; 2018 [cited 2021 Jun 12]. Available from: http://www.intechopen.com/books/dental-cariesdiagnosis-prevention-and-management/therelationship-between-orthodontic-treatment-anddental-caries

19. Schifter CC, Emling RC, Seibert JS, Yankell SL. A comparison of plaque removal effectiveness of an electric versus a manual toothbrush. Clin Prev Dent. 1983 Oct;5(5):15-9. 